\title{
Seasonality at the Karachi Stock Exchange
}

\author{
Syed Ifran Ahmed* \\ Dr. S. M. Husnain Bokhari
}

\begin{abstract}
Generally, calendar effects takes place when the returns of financial assets exhibit particular characteristics over specific days, weeks, months or even years. This research report uses dummy variables with multiple linear regressions to identify the existence of various effects. Which include month-of-the year effect or January effect, turn-of-theyear effect, summer effect, month-of-the quarter effect, week-of-the month effect, semi month effect, day-of-the-week effect or weekend effect, Monday effect, holiday effect, and Ramadhan effect. The study was done on the Karachi Stock Exchange using the KSE-100 Index.
\end{abstract}

The study concluded that several seasonal effects do exist in the KSE. Some of the effects that were found included day 3 as the day-of-the-week effect; January, February, May indicate month-of-the-year effects; weeks 3, 5, 7, 21 and 22 show week-of-theyear effect and Ramadhan effect. These effects indicate that the returns are significantly higher in these periods/seasons. The implications from the existence of these effects are the opportunity of making excessive returns in relation to the risk taken. There is also an indication of Weak or Semi strong form of Efficient Market Hypothesis for the KSE. While this study has provided additional insights into the behavior of stock returns in emerging markets, stock returns seasonality is still not fully understood.

Keywords: KSE, seasonality, stock returns, efficient market.

\section{Introduction}

Usually, when the returns of financial assets exhibit particular characteristics over specific days, weeks, months or years; the calendar effects take place. Certainly, this is in contradiction to supporting the hypothesis of efficient market in which returns ought to be random and also should not be related with a specific time period. Nevertheless, several studies have witnessed the presence of calendar effects on numerous stock markets. Such as French (1980), Gibbons and Hess (1981), Keim and Stambaugh (1984) investigated the presence of a Monday effect on the US market. Also, Jaffe and Westerfield (1985) determined that mean returns were lowest on Tuesday on the Australian and Japanese stock markets. Furthermore, Brooks and Persand (2001) examined the week day's effect on five South East Asian stock markets and concluded that there are some positive Monday effects on the Malaysian and Thailand stock exchange. In reality, gains on a particular time period may be insignificant when transactions costs are taken into account.

\footnotetext{
* Syed Irfan Ahmed is working at Pak Kuwait Investment Company (PKIC) as Senior Officer (Investment Banking Division), irfimail@yahoo.com

Dr. S. M. Husnain Bokhari is working in State Bank as Joint Director, Statistics \& Data Warehouse Department
} 


\subsection{Karachi Stock Exchange}

Founded in 1947 and located in Karachi, the Karachi Stock Exchange (KSE) is Pakistan's largest, with most liquid and oldest stock exchange, with many Pakistani as well as overseas listings. Its current premises are situated on Stock Exchange Road, in the heart of Karachi's business district.

Karachi Stock Exchange was declared as the 'Best Performing Stock Market of the World for the year 2002'. As on May 30, 2008; 654 companies were listed with a market capitalization of Rs. 3,746.203 billion (US $\$ 56.334$ billion) having listed capital of Rs. 705.873 billion (US $\$ 10.615$ billion).

Year after year KSE has proved to be an outstanding market for local as well as foreign investors. It has been declared as Best Performing Markets of the world for four times by the international magazine 'Business Week'. Similarly the US newspaper, USA Today, termed Karachi Stock Exchange as 'one of the best performing bourses in the world'. However, in the last six or seven months the stock exchange has seen an almost precipice fall and has reduced to almost two thirds it size from a once globally acclaimed growth oriented stock exchange.

The Graph below shows phenomenal performance that KSE has shown over the past decade.

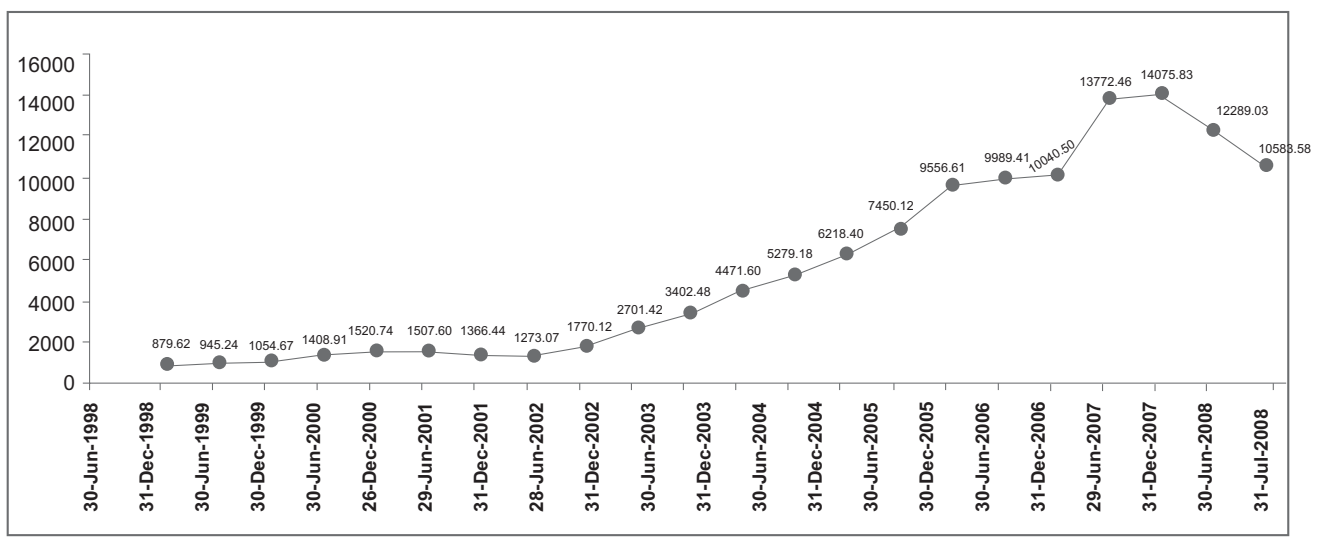

Source: KSE

Currently KSE has four different Market indices and these are KSE-100, KSE-30, $\mathrm{KMI}-30$ (Islamic Index) and the KSE-ALL index.

\subsection{Statement of the Problem}

Seasonality effects have several pros and cons. Seasonal effects provide investors with an opportunity to gain excess returns coupled with lower risks. It is important for Professional Investment Companies, Asset Management Companies, Funds and individuals to understand the impact of seasonality and its effects as it plays a vital role 
in the market-changes and also to formulate strategies in particular portfolio choices to capitalize existing profit opportunities present because of calendar and seasonal anomalies. In this study, we have inspected the effect of seasonality (day-of-the-week effect, week-day effect, monthly effect on stock returns).

\subsection{Objective of the Study}

The main objective of the study is to investigate the effects of any seasonality on stock market returns and volatility on the Karachi Stock Exchange. Day-of-the-week effect, week-day effect, monthly effect, holiday effect on stock returns are tested on stock returns and not in all but in some of the cases it is found to be significant.

\subsection{Key Research Questions}

1) Why do seasonal effects exist?

2) Is there a day of the week effect in the Karachi Stock Exchange Index?

3) Is there a holiday effect in the Karachi Stock Exchange Index?

4) Is there a month-of-the-year effect in the Karachi Stock Exchange Index?

5) Are there moving calendar anomalies and seasonality in the Karachi Stock Exchange Index because of differences in Islamic and conventional calendars?

6) Other Seasonality effects on the Karachi Stock Exchange Indexes?

\section{Literature Review}

\subsection{Past Studies}

Seasonal anomalies or calendar effects in securities markets have been much discussed. There are several research papers that have studied calendar or time anomalies. Cross (1973) and French (1980) investigated and concluded that on average, and over a sustained period of time, the returns and closing prices end up being lower on Monday evenings in comparison to their counter part values on Fridays. Cross (1973) and French (1980) investigated the day-of-the-week effect or Weekend effect and confirmed its existence through their research. French (1980), Barone (1990) and Gibbons \& Hess (1981) conducted a similar research and concluded their research that, on average, Mondays has lower returns than any other day of the week. They further stated that the biggest fall in stock prices took place in the first two days of the week.

Guin (2005) stated that the weekend effect can be related to those companies and governments which tend to realize bad news over the weekends and thus explaining the logic behind the existence of day-of-the-week effect or Weekend effect behavior. Foster and Wiswanathan (1990) maintain that information symmetry was the cause behind the difference in trading volumes on Fridays and Mondays as opposed to other days. 
Balaban, Bayer and Kan (2001) have researched 19 countries to identify day of the week effect. The countries included were Australia, Austria, Belgium, Canada, Denmark, Finland, France, Germany, Hong Kong, Italy, Japan, Netherlands, New Zealand, Norway, Spain, Sweden, Switzerland and UK. Ho (1990) had tested 10 different Asia Pacific countries. No study has been carried out on Pakistan to identify day-of-the-week effects. Numerous authors, who have studied various countries, prove the existence of the dayof-the-week-effect and affirm the global phenomenon it truly is.

Keim (1983), Ariel (1987), and Haugen and Jorion (1996) concluded that the Stock prices in January are much higher then the stock prices in December. On the other hand, Givoly and Ovadia (1983) in their investigation of the Turn-of-the-year-effect studied had stated that the traded volume is much larger in January and December. Guin (2005) said that the reason behind trading volumes being large at the turn of the year or beginning of the year is because of tax-related issues, which involves selling in December and buying in January. The relationship stated by Guin (2007) was seconded by Sigi and Zhiqiang (2007). They claimed that January effect exists because of tax-loss selling hypothesis. This hypothesis states that the losing stocks are sold until the end of the tax year. They tried to increase the capital losses, which can lead to a much warranted reduction in the burden of the tax liability. They stated that the declining stocks face downward pressures, but the new year releases this downward pressure therefore the stock prices can gain their real market value. Month-of-the-quarter effect was studied by Penman (1987) where he concluded that higher rate of returns are seen in first month of the quarter by various firms. Wachtel (1942) in his efforts to study the summer effect discovered evidences of rising stock prices in the summer time.

Linn \& Lockwood (1988) and Hensel and Ziemba (1996) had analyzed the Week-ofthe-month-effect. They confirmed that stocks usually have return anomalies. They went further and stated that the first week of the month gives higher returns than the last three. Week-of-the-year or week-of-the-month effects partly follow similar reasoning as month-of-the-year effects and can happen because of financial results or important events or seasonal announcements by national, domestic, local, regulatory and/or federal authorities as the release of monetary policy by State Bank.

Fazal (1998) in his research on Pakistan Equity Markets concluded that returns are lower for various firms in Pakistan during the holy month of Ramazan. Lakonishok \& Smidt (1988) and Petengill (1989) have stated that Stock markets depict higher and more than normal returns before public holidays in their research on the Holiday effect.

\subsection{Econometric Methodology}

Various authors have used various methods for identifying seasonal variation in stock exchanges. The methodologies used to test stock market anomalies can be divided into two categories. One category belongs to the Logarithmic Model and the other to the Generalized Autoregressive Conditional Heteroscedasticity (GARCH) Model and its variations.

Unconditional logarithmic returns in OLS based regressions with dummy variables have 
been used by (Ercan Balaban,1994),(Akhtam 2002), (Ushad 2008) and (Marcus 2006). The model is fairly easy to implement and serves as a good start up point to identify anomalies. The logarithmic model studies return anomalies.

Several authors have used the GARCH model. Variations include Exponential Generalized Autoregressive Conditional Heteroscedasticity in mean (EGARCH-M) model by (Ricky Venus \& others 2007), (Akhtam 2003) and (Ushad 2008) to test day of the week effects. Periodic AutoRegressive model (PAR) which allows the autoregressive parameters to vary with the day of the week considered in Abraham and Ikenberry (1994). Bollerslev and Ghysels (1996) use a periodic GARCH model (PGARCH) coupled with a PAR model for the mean to study the non-trading effect in exchange rates. PAR-PGARCH model introduced in (Franses - Paap, 2000) to investigate the seasonality in daily returns and variation of the PAR-PGARCH model (Filip ZIKE-Vít BUBÁK, 2006) to identify seasonal day of the weak effects. (Ushad 2008) has used the threshold GARCH, or TGARCH model of Rabemananjara and Zakoian (1993) and Zakoian (1994) based on the asymmetric nature of shocks. GJR model proposed by Glosten et al. (1993) extends the GARCH model to allow for asymmetric effects and has been used by (Akhtam 2003) to identify January effect. The GJR model is closely related to the threshold GARCH, or TGARCH Model.

Using GARCH models entail several advantages in that they help in capturing the characteristics of financial time series. For instance, they allow for volatility clustering and leverage effects. According to Engel (1982), Bollerslev (1986) and Bollerslev et al. (1992), autoregressive conditional Heteroscedasticity models (GARCH) are more appropriate as they are more flexible in capturing dynamic structures of conditional variance. The GARCH Model studies variance and volatility anomalies.

\section{Research Methodology}

This study will use unconditional logarithmic returns in OLS based regressions with dummy variables to identify seasonality. The study will also be using descriptive statistics to obtain the three measures of central tendency, such as the mean, median, and mode, and two measures to visualize the shape of the curve with respect to symmetry and flatness by calculating the skew- ness and kurtosis of the data. The results, if required, will be corroborated with GARCH models. Studying volatility effects hold their own importance but for KSE and in particular Pakistan and emerging economies like Fama (1999) suggested the study of returns are far more important to identify anomalies and to profit of them then the volatility of returns.

E-views software has been used to analyze and evaluate the data. Excel was used to identify, generate and test dummy variables. The same sorted and aligned dummy variables were used as input to multiple regression models (stated below).

\subsection{Sample Data and Source}

The sample has been taken from KSE -100 Index from December 1, 1994 to October 20, 2008. It has 3360 observations out of a possible 5072 observations. Holidays have 
been removed from the total set of possible observations. With respect to the day of the week effect, the sample has been further reduced to 2836 observations and covers the data from March 3, 1997 to October 20, 2008. This is because Pakistan had Friday as national holiday up until March 1997. Until 1997, Sunday would be considered as first trading day, after March 1997 Monday was the first trading day. The data have been taken from KSE as given on their website from the period as stated above.

It is important to address a few yet very valid concerns related to sample data. Firstly, there was a change in trading days that is prior to 1997; Friday was the national holiday with Sunday being first trading day. As mentioned above, the sample used for certain models is only after 1997. Secondly, in addition to changes in trading days the market remained depressed till the end of 2001. From December 2001 to March 2005 it was in full swing. It remained volatile. After March crash, it did well in the first part of 2006 but crashed again in June. After doing generally well in 2007, it remained in trouble for most of the time in 2008. At first glance, it seems any analysis on such a sample would not give any meaningful results. Thus the sample should be divided in different phases and then tested with separate models. As genuine the concern is but Chowtest has confirmed that the used data (i.e natural log of returns) is stable and there is no structural break.

\subsection{Econometric Models}

Following is a list of Models to be used depending on the effects to be studied. Please note in all models $\mathrm{Y}$, the dependent variable is equal to in (KSE-100 index at day $n$ / KSE-100 index at day $n-1$ ).

\subsubsection{Day-of-the-Week Effect}

The following econometric model is tested:

$Y=B 1 D 1+B 2 D 2+\ldots . B 5 D 5+e$

Where D1, D2, D3... is the dummy variables for each day.

The model will test day-of-the-week effect, weekend-effect and Monday-effect.

\subsubsection{Holiday Effect}

The following econometric model is tested:

$Y=B 1 B H+B 2 A H+e$

Where $\mathrm{BH}, \mathrm{AH}$, is the dummy variables used for before holiday and after holiday to study the holiday effect.

\subsubsection{Week-of-the-Year Effect}

The following econometric model is tested:

$Y=B 1 W 1+B 2 W 2+\ldots . . B 52 W 52+e$

Where $\mathrm{W} 1, \mathrm{~W} 2, \mathrm{~W} 3 \ldots$ is the dummy variables for each week.

Week-of-the month effect, Semi Month effect will be tested using this model. 


\subsubsection{Month-of-the-Year Effect}

The following econometric model is tested:

$Y=B 1 M 1+B 2 M 2+\ldots . B 12 M 12+e$

Where M1, M2, M3... is the dummy variables for each month.

It is used to test Month-of-the year effect or January effect, turn-of-the-year effect, summer effect, month-of-the quarter effect, political-cycle effect and so forth.

\subsubsection{Ramadhan Effect}

The Ramadhan Effect is tested separately because of the fact that Islamic / Lunar calendars are different from the conventionally used Roman calendar. The Econometric model used is:

$Y=B 1 R 1+e$

Where, R1 is the dummy variable for month. Dummy variable will be set to 1 for Ramadhan and Zero for all other months.

\subsubsection{Quarter-of-the-Year Effect}

The following econometric model is tested:

$Y=B 1 Q 1+B 2 Q 2+\ldots . . B 4 Q 4+e$

Where Q1, Q2, Q3... is the dummy variables for each Quarter.

The model will study financial results effect, quarterly effect etc.

\subsection{Results Interpretation and Identifying of Effects}

As stated above any effects will be discovered through running multiple regressions with dummy variables. These coefficients of the dummy variables will be tested to see if the mean is zero or not.

The hypothesis test steps used for testing mean value of coefficients for all models is as follows:-

$H O$; mean of coefficient $=0$

$H A$; mean of coefficient $\neq 0$

Effects will be judged with $95 \%$ confidence interval $(\alpha=5 \%)$ or P-Value of less then 0.05 . Any P-Value found below the 0.05 mark will be judged as having an effect.

The test statistics along with detailed results will be obtained though E-Views software.

\section{Analysis and Results}

The analysis section is broadly divided into two sections. The first tests KSE 100 Index data for normality. Non-Normal data cannot be used in regression. Therefore, it is important to make the model(s) in such a way that the distribution of sample fits the normality criteria. The second section deals with the results of various models run on e-views along with interpretation. 
KSE-Data: In order for any form of regression analysis to be done on any data, the data must satisfy certain conditions. If we look at the KSE-100 index data below we are going to see an upward trend with lots of disturbances. Therefore, the KSE data were transformed to perform regression analysis.

For exponential trends similar to KSE-Hundred index, either taking logs or a first differential is suggested. We take the In (log to base e) of returns from the KSE-100 index. Here

$\mathrm{Y}=\ln (\mathrm{KSE}-100$ index at day $\mathrm{n} / \mathrm{KSE}-100$ index at day $\mathrm{n}-1$ )

The transformed data were found to fit for regression modeling.

\subsection{Regression Model Results}

\subsubsection{Day-of-the-Week Effect}

The model tested and results for the regression model are as follows: $Y=B 1 D 1+B 2 D 2+\ldots . . B 5 D 5+e$

\begin{tabular}{|c|c|c|c|c|}
\hline Variable & Coefficient & Std. Error & t-Statistic & Prob. \\
\hline DAY1 & -0.000356 & 0.000738 & -0.483039 & 0.6291 \\
\hline DAY2 & 0.000547 & 0.000743 & 0.736344 & 0.4616 \\
\hline DAY3 & 0.001803 & 0.000736 & 2.450944 & 0.0143 \\
\hline DAY4 & 0.000466 & 0.000746 & 0.624670 & 0.5322 \\
\hline DAY5 & 0.000275 & 0.000755 & 0.364494 & 0.7155 \\
\hline
\end{tabular}

Regarding the day-of-the-week effect, there is a Day 3 effect. If we look at the t-statistics value of day 3 , we note that unlike all other days, this day has a much higher t-statistic value. It also has a P-Value of 0.0143 which is well below our benchmark of 0.05 . At $95 \%$ significance level, we reject the Null Hypothesis which states that there is no day effect and conclude that there may be a Day 3 effect. We can see that the returns on the third day have been higher in general to other days. Weekend effect and Monday effect clearly do not exist. There is no significant difference in the results on first and fifth day of trading at KSE.

\subsubsection{Holiday Effect}

The model tested and results for the regression model are as follows: $Y=B 1 B H+B 2 A H+e$

\begin{tabular}{|c|c|c|c|c|}
\hline Variable & Coefficient & Std. Error & t-Statistic & Prob. \\
\hline C & 0.000753 & 0.000440 & 1.713396 & 0.0867 \\
\hline DAY_BEFORE & -0.000460 & 0.000799 & -0.575614 & 0.5649 \\
\hline DAY_AFTER & -0.000405 & 0.000799 & -0.506607 & 0.6125 \\
\hline
\end{tabular}


If we see all test statistics, we observe that all statistics have a p-value of more then 0.5 . Therefore we fail to reject the null hypothesis and conclude that there is no day effect before or after holidays. This indicates that trading before or after holidays do not offer additional returns.

\subsubsection{Week-of-the-Year Effect}

The model tested and results for the regression model are as follows: $Y=B 1 W 1+B 2 W 2+\ldots . B 52 W 52+e$

\begin{tabular}{|c|c|c|c|c|}
\hline Variable & Coefficient & Std. Error & t-Statistic & Prob. \\
\hline WEEK21 & -0.005742 & 0.002106 & -2.726156 & 0.0064 \\
\hline WEEK22 & -0.004141 & 0.002106 & -1.965831 & 0.0494 \\
\hline WEEK3 & 0.005718 & 0.002190 & 2.611235 & 0.0091 \\
\hline WEEK5 & 0.004352 & 0.002208 & 1.971283 & 0.0488 \\
\hline WEEK7 & 0.005290 & 0.002122 & 2.492619 & 0.0127 \\
\hline
\end{tabular}

If we see all test statistics we observe that with the exception of Weeks 3, 5, 7, 21 and 22 all other weeks have low t-statistics and a p-value of more than 0.5 . Therefore, we fail to reject the null hypothesis and conclude that there is no week of the year effects for all weeks except Weeks 3, 5, 7, 21 and 22.

We also note that p-value for Weeks 3, 5, 7, 21 and 22 are below 0.05 . Therefore, we reject the null hypothesis and conclude that there may be week-of-the-year effects for Weeks 3, 5, 7, 21 and 22. With the data we can also conclude that there is no Weekof-the-month effect because majority of results are insignificant. Semi-month effect is also not seen at the KSE.

\subsubsection{Month-of-the-Year Effect}

The model tested and results for the regression model are as follows: $Y=B 1 M 1+B 2 M 2+\ldots . B 12 M 12+e$

\begin{tabular}{|c|c|c|c|c|}
\hline Variable & Coefficient & Std. Error & t-Statistic & Prob. \\
\hline Month 1 & 0.002364 & 0.001018 & 2.322085 & 0.0203 \\
\hline Month 2 & 0.002716 & 0.001089 & 2.494827 & 0.0126 \\
\hline Month 5 & -0.003132 & 0.001020 & -3.071304 & 0.0021 \\
\hline
\end{tabular}

The regression results indicate that with the exception of January, February and May, all other months have low t-statistics and a p-value of more than 0.5 . Therefore, we fail to reject the null hypothesis and conclude that there is no month of the year effects for all months except months of January, February and May. 
We also note that p-value for months - January, February and May-are below 0.05 . Therefore we reject the null hypothesis and conclude that there may be month of the year effects for Months January, February and May. January, February and May indicate Month of the Years Seasonal effects. The January effect may also be termed as the Turn of the Year effect. Summer effect and Month-of-the-quarter effects are also absent in the KSE.

\subsubsection{Ramadhan Effect}

The model tested and results for the regression model are as follows:

$Y=B 1 R 1+e$

\begin{tabular}{|c|c|c|c|c|}
\hline Variable & Coefficient & Std. Error & t-Statistic & Prob. \\
\hline $\begin{array}{l}\text { RAMDHAN_ } \\
\text { DUMMY }\end{array}$ & 0.003365 & 0.001050 & 3.204899 & 0.0014 \\
\hline C & 0.000138 & 0.000311 & 0.442599 & 0.6581 \\
\hline
\end{tabular}

With a P-value of 0.0014 (well below the limit level of 0.05 ), we reject the null hypothesis that coefficient value equals zero and conclude that there may be a Ramadhan Effect. The results show that there is a significant rise in returns during Ramadhan.

\subsubsection{Quarter-of-the-Year Effect}

The model tested and results for the regression model are as follows:

$Y=B 1 Q 1+B 2 Q 2+\ldots . . B 4 Q 4+e$

\begin{tabular}{|c|c|c|c|c|}
\hline Variable & Coefficient & Std. Error & t-Statistic & Prob. \\
\hline QUARTER1 & 0.001591 & 0.000597 & 2.664358 & 0.0078 \\
\hline QUARTER2 & -0.000772 & 0.000589 & -1.311459 & 0.1898 \\
\hline QUARTER3 & 0.000250 & 0.000584 & 0.427355 & 0.6691 \\
\hline QUARTER4 & 0.000719 & 0.000610 & 1.179204 & 0.2384 \\
\hline
\end{tabular}

For the first quarter, with a high t-Statistic of 2.664358 and a low P-value of 0.0078 (well below the limit level of 0.05 ) we reject the null hypothesis that coefficient value equals zero and conclude that there may be a quarter-of-the-year effect for the first quarter. This indicates the possibility of higher returns in the first quarter of the year. On the contrary we fail to reject the null hypothesis for all other quarters in the year and conclude that there is no quarter of the year effects for second third and fourth quarters. 


\section{Conclusion}

In our study we have seen that several seasonal effects do exist in the KSE. Some of the effects that were seen are as follows:

- $\quad$ Day 3 as the Day-of-the-week effect

- January, February, May indicate Month of the Year effects

- Weeks 3, 5, 7, 21 and 22 show week of the Year effects and

- $\quad$ The Ramadhan Effect.

These effects indicate that the returns are significantly higher in these seasons. The implications from the existence of these effects are the opportunity of making excessive returns in relation to the risk taken. There is also an indication of Weak or Semi strong form of Efficient Market Hypothesis for the KSE. While this study has provided additional insights into the behavior of stock returns in emerging markets, comprehensive stock returns seasonality still is not fully understood.

Future researchers can further verify findings by using additional test like the Kruskil Wallis test for Day of the week effect; whereas other researchers can ventures into several other effects that have been studied in international markets. 


\section{References}

1 Abraham, A., Ikenberry, D. L., (1994) 'The individual investor and the weekend effect,'Journal of Financial and Quantitative Analysis, pp. 263-278.

2 Aktham, Maghayereh (2002) 'Seasonality and January effect anomalies in an emerging capital market', The Hashemite University.

3 Ariel, Robert A. (1987) 'A monthly effect in stock returns', Journal of Financial Economics, Vol. 18, pp. 161-174.

4 Barone, E (1990) 'The Italian stock market: efficiency and calendar anomalies', Journal of Banking and Finance, Vol. 14, pp. 483-510.

5 Bollerslev, T. (1986) 'Generalized Autoregressive Conditional Heteroscedasticity', Journal of Econometrics, Vol. 31, pp. 307-27.

6 Brooks, C. and Persand, G. (2001) 'Seasonality in Southeast Asian stock markets: some new evidence on day-of-the-week effects', Applied Economic Letters, Vol. 8, pp. 155-158.

7 Cross, $\mathrm{F}$ (1973) 'The behavior of stock prices on Fridays and Mondays', Financial Analysts Journal, Vol. 31, pp. 67-69.

8 Engle, R.F. (1982) 'Autoregressive conditional heteroscedasticity with estimates of variables of UK inflation,' Econometrica, Vol. 50, pp. 987-1008.

9 Ercan Balaban (1994) ', 9410, Research and Monetary Policy Department, Central Bank of the Republic of Turkey.

10 Fama, E. (1999) 'Efficient capital markets: I', Journal of Finance, Vol. 46, pp.1575-617.

11 Fazal Hussain (1998) 'Seasonality in Pakistan equity market: the Ramadhan effect', Pakistan Development Review, Vol. 37, No.1

12 Filip ZIKES-Vít BUBÁK, (2006) 'Seasonality and the non-trading effect on central European stock markets', Institute of Economic Studies, Faculty of Social Sciences, Charles University, Prague.

13 Foster, D. and Wiswanathan, S. (1990) 'A theory of the interday variations in volume, variance, and trading costs in securities markets,' Review of Financial Studies, Vol. 3.

14 Franses - Paap, (2000) 'Modelling day-of-the-week seasonality in the S\&P 500 index,' Applied Financial Economics, Vol. 10, No. 5 (September), pp. 483-488. 
15 French, K (1980) 'Stock returns and the weekend effect', Journal of Financial Economics, (March) Vol. 8, No. 1, pp. 55-69.

16 Guin, L. (2005) Handout on market anomalies in the course Investment Management, Professor in finance, department of Economics and Finance, Murray State University.

17 Gibbons, M. and Hess, P. (1981) 'Day of the week effects and asset returns', Journal of Business, Vol. 54, pp. 579-596.

18 Givoly, D. and Ovadia, A. (1983) Year-end induced sales and stock market seasonality, Journal of Finance, Vol. 38, pp. 171-185.

19 Glosten, L. R., Jagannathan, R., and Runkle, D. E. (1993) On the relation between the expected value and the volatility of the nominal excess return on stocks, Journal of Finance, Vol. 48, No. 1, pp. 779-801.

20 Haugen, R. and Jorion, P. (1996) 'The January effect: still here after all these years' Financial Analysts Journal (January-February), pp. 27-31.

21 Hensel, C. and Ziemba, W. (1996) 'Investment results from exploiting turn-of-themonth effects, Journal of Portfolio Management, spring.

22 Jaffe, J., and R. Westerfield (1985) 'The weekend effect in common stock returns: the international evidence,' Journal of Finance, pp. 433-454.

23 Keim, D. and Stambaugh, R. (1984) 'A further investigation of the weekend effect in stock returns', Journal of Finance, pp. 819-835.

24 Linn, S. and Lockwood, L. (1988) Short-term stock price patterns: NYSE, AMEX, OTC, Journal of Portfolio Management, winter, pp. 30-34.

25 Mahhayereh, A. (2003) 'Seasonality and January effect anomalies in an emerging capital market', The Arab Bank Review, Vol. 5, pp. 25 -32.

26 Marcus Davidson, (2006) 'Stock Market Anomalies', Jonkoping International Business School.

27 Penman, S. (1987) 'The distribution of earnings news over time and seasonalities in aggregate stock returns, Journal of Financial Economics, Vol. 18, pp. 199-228.

28 Pettengill, G. (1989) 'Holiday security returns', Journal of Financial Research, Vol. 12, pp. 57-67.

29 Ricky C. J. Chia, Venus K.S. Liew, SAWSK Wafa,(2008), , Economics Bulletin 2008 -economicsbulletin.vanderbilt.edu 
30 R. Rabemananjara and J. M. Zakoian ,(1993) Threshold Arch Models and Asymmetries in Volatility ,Journal of Applied Econometrics, (Jan-Mar), Vol. 8, No. 1 pp. 31-49

31 Sigi Gao and Zhiqiang Wang (2007) 'Market efficeincy anomilies,' Umea' School of Business, Master Thesis.

32 Ushad (2008) Monthly anomalies on the Mauritian equity market: evidence from GARCH models, Oxford Business and Economics Conference Program.

33 Zakoian, J. M. (1994) Threshold heteroscedastic models, Journal of Economic Dynamics and Control, Vol. 18, pp. 931-955. 